\title{
Sociodemographic Determinants of Personality Disorder In Patients of Obsessive-compulsive Disorder
}

\author{
ASM Morshed ', Sultana Algin ${ }^{2}$, Ashraf Uddin Ahmed ${ }^{3}$, Mahjabeen Aftab Solaiman $^{4}$, Saif Bin Mizan ${ }^{5}$, Rubaiya Khan $^{6}$
}

\begin{abstract}
Background \& objective: Obsessive Compulsive Disorder (OCD) is the 4th most prevalent psychiatric disorder in Epidemiological Catchment Area (ECA) Survey and most individuals with OCD have co-morbid personality disorders (PD). The present study was undertaken to find the prevalence of PD among patients with OCD and the sociodemographic determinants that influence the development PD in patients with OCD.

Methods:The cross-sectional analytical study was conducted in OCD clinic of Bangabandhu Sheikh Mujib Medical University from January 2015 to September 2016. Respondents were recruited from the OCD patients diagnosed on the basis of DSM-IV criteria and face to face interview was conducted with the help of the Structured Clinical Interview for DSM-IV Axis II Disorders (SCID-II questionnaire). The main outcome variable was PD in patients of $\mathrm{OCD}$ and the exposure variables (determinants) were selected sociodemographic characteristics.

Result: The mean age of the OCD patients was ( $28 \pm 8.7)$ years. Almost half $(49 \%)$ of OCD patients belonged to the age group 20-30 years. Female respondents were $53.6 \%$. Among the respondents, $62 \%$ had co-morbid PD. The mean age of the OCD patients with PD was observed to be significantly higher ( $29.1 \pm 9.1$ years) than those without PD $(26.2 \pm 7.8$ years) $(p=0.047)$. Male OCD patients were $2.4(95 \%$ CI of OR: $1.2-4.7)$ times more likely to have PD than their female counterparts $(p=0.012)$. Ethnic groups other than Muslims tend to be associated with PD more often and carry more than 8-fold (95\% CI of OR: $8.4-37.2$ ) higher risk of having the condition $(p=0.001)$. Likewise, other occupants were nearly $2(95 \%$ CI of OR: $0.98-3.74)$ times more prone to have PD than the students $(p=0.056)$.

Conclusion: Personality Disorders are highly prevalent among people with OCD which remains underdiagnosed $\&$ under-addressed. Male OCD patients, non-Muslims and occupants other than students are more prone to have PD. Persons with Personality Disorders are far more likely to refuse psychiatric help and deny their problems.
\end{abstract}

Key words: Personality Disorder, Obsessive Compulsive Disorder, Bangladesh.

\section{INTRODUCTION:}

The study of obsessive-compulsive disorder (OCD) has raised an increasing interest in different fields over the last few years. The study of personality disorder in individuals with OCD has intrigued researchers $\&$ clinicians for many years, but remains controversial. The association between OCD and personality disorders (PD) is one of the best-known relationships between mental state and personality. OCD is the $4^{\text {th }}$ most prevalent psychiatric disorder in Epidemiological Catchment Area (ECA) Survey ${ }^{1}$ and the $10^{\text {th }}$ most disabling of all medical disorders in an

\section{Authors' information:}

${ }^{1}$ Dr. ASM Morshed, Assistant Professor, Department of Psychiatry, Dr. Sirajul Islam Medical College, Dhaka, Bangladesh.

${ }^{2}$ Dr. Sultana Algin, Associate Professor, Department of Psychiatry, Bangabandhu Sheikh Mujib Medical University, Dhaka, Bangladesh.

${ }^{3}$ Dr. Ashrafuddin Ahmed, Resident Physician, Birdem General Hospital, Dhaka, Bangladesh.

${ }^{4}$ Dr. Mahjabeen Aftab Solaiman, Assistant Professor, Department of Psychiatry, President Abdul Hamid Medical College, Kishoegonj, Bangladesh.

${ }^{5}$ Dr. Saif Bin Mizan, Assistant Professor, Department of Nephrology, Dr. Sirajul Islam Medical College, Dhaka, Bangladesh.

${ }^{6}$ Dr. Rubaiya Khan, MD Resident, Department of Psychiatry, Bangabandhu Sheikh Mujib Medical University, Dhaka, Bangladesh.

Correspondence: Dr. ASM Morshed, Cell Phone: +8801711-193888 Email: h/wromel@yahoo.com 
early burden of disease study. The lifetime prevalence rates of OCD (range 1.9-2.5\%) and annual prevalence rates of OCD (range 1.1-1.8\%) are remarkably consistent across countries except Taiwan. ${ }^{2}$ Prevalence of OCD in Bangladesh is $0.5 \% .^{3}$

The clinical condition of OCD is characterized by the presence of obsessions or compulsions. An obsession is a recurring and persistent thought, idea, or image, which is experienced in a parasitic way and its content is usually undesirable and produces anxiety; it is involuntary and disturbs the course of the subject's normal thought activity. Sometimes, it is accompanied by the need to perform a certain action (either behavior or other thoughts), which is performed as a compulsion or obsessive ritual with the aim of reducing the feeling of distress. Reported age at onset is usually during the adolescence. The onset for males occurred significantly earlier than for females and $83 \%$ of patients experienced the onset of significant symptoms between ages 10 and 24 years. ${ }^{4}$ OCD is found more common in female $(67.8 \%)$ than male $(32.2 \%)$ in Bangladesh. ${ }^{3}$

Persons with OCD are commonly affected by other mental disorders. The lifetime prevalence for major depressive disorder in persons with $O C D$ is about $67 \%$ \& for social phobia about $25 \%$. Other common co-morbid psychiatric diagnosis in OCD patients includes alcohol use disorder, generalized anxiety disorder, specific phobia, panic disorder, eating disorders and personality disorders. OCD exhibits a superficial resemblance to obsessive compulsive personality disorder. Personality Disorder (PD) is an enduring pattern of behavior and inner experiences that deviates significantly from the individual's cultural standards; is rigidly pervasive; has an onset in adolescence or early adulthood; is stable through time; leads to unhappiness and impairment; and manifests in at least two of the following four areas: cognition, affectivity, interpersonal function, or impulse control. PD symptoms are ego syntonic and alloplastic (adapt by trying to alter the external environment rather than themselves). ${ }^{5}$

Personality Disorders are classified according to DSM-IV into three clusters. The clusters are based on descriptive similarities. Cluster $A$ includes three PDs with odd, aloof features (Paranoid, Schizoid and
Schizotypal). Cluster B includes four PDs with dramatic, impulsive and erratic features (Borderline, Anti-social, Narcissistic and Histrionic). Cluster C includes three PDs sharing anxious \& fearful features (Avoidant, Dependent and Obsessive Compulsive). Other than these ten types of PDs, there are two other types; Depressive and Passive-Aggressive. Individuals frequently exhibit traits that are not limited to a single PD. When a patient meets the criteria for more than one $P D$, clinician/researcher should include each. ${ }^{5}$ Among those with $O C D$, the prevalence of individual categories of PD appears to vary between the sexes. Men with $O C D$ are more likely to meet diagnostic criteria for anti-social, ${ }^{6}$ schizotypal ${ }^{7}$ or obsessive-compulsive personality disorder (OCPD), ${ }^{8}$ while borderline and dependent personality disorders appear to be more frequent among women.?

The co-morbidity of OCD and PDs has been studied more systematically since the establishment of a separate axis for PD in DSM-III. ${ }^{9}$ Recent studies, employing structured assessments, have shown that most individuals with OCD meet criteria for at least one co-morbid $\mathrm{PD}$, usually from the anxious cluster, although only a minority has OCPD. ${ }^{10-12}$ Thus, other personality patterns, usually mixed types, seem to occur more frequently in OCD. ${ }^{13}$ However, which of the specific cluster among others obtains the highest prevalence depends on which version of the DSM is used for the assessment of PDs. The prevalence of OCPD in a sample of OCD patients increased when DSM-III-R criteria were applied instead of DSM-III criteria. ${ }^{14}$ Assessments of PD in OCD patients are scarce according to DSM-IV criteria. In one study using DSM-IV, a predominance of Cluster C PDs was found, with the majority of patients fulfilling criteria for OCPD. ${ }^{15}$ In Bangladesh, by far, no study has yet been done to measure the PD among OCD population. So, the present study aims to investigate the prevalence of PD among OCD patients and the socio-demographic variables that determine the development of PD in OCD patients.

\section{METHODS:}

This cross-sectional analytical study was carried out on Bengali speaking patients with Obsessive Compulsive Disorder attending in Obsessive Compulsive Disorder 
(OCD) Out-Patient Clinic of the Psychiatric Department (OPD) at Bangabandhu Sheikh Mujib Medical University (BSMMU), Dhaka, Bangladesh over a period of 19 months from January 2015 to September 2016. A total of 151 patients of both sexes, aged $\geq 18$ years or above diagnosed as having OCD based on DSM-IM-IV criteria were consecutively included in the study. However, patients who is psychotic, mute, non-communicable and having serious medical illness and cognitive impairment were excluded from the study. A three-phase approach has been used for data collection. The researcher carried out initial structured interviews. The full assessment of OCD was done in the first phase of the survey by an expert consultant of psychiatry in OCD clinic of BSMMU. After meeting all the eligibility criteria, sociodemographic information was taken by the researcher in second phase and in last phase, the SCID-II questionnaire was applied to screen for Personality Disorders among the OCD patients by face to face interview complying with all ethical issues.

Data analysis was performed by statistical package for social science (SPSS), version-17. The test statistics used to analyze the data were Chi-square or Fisher's Exact Test and Unpaired t-Test. Data presented on categorical scale were compared between groups (with and without OCD) using Chi-square $\left(\chi^{2}\right)$ or Fisher's Exact Test, as appropriate, while the data presented on continuous scale were compared between groups using Unpaired t-Test. The level of significance was set at $5 \%$ and $p<0.05$ was considered significant.

\section{RESULTS:}

\section{Demographic characteristics:}

Almost half $(49 \%)$ of the OCD patients belonged to the age group 20-30 years with mean age of the patients being 28 years (range: 13-60 years). Females were a bit higher (53.6\%) than the males $(46.4 \%)$. Majority $(84.1 \%)$ of the patients was Muslim. In terms of occupation, students formed $41.1 \%$, followed by housewives $(31.1 \%)$, service holder $(12.6 \%)$, unemployed $(9.9 \%)$, businessman $(2.6 \%)$, others $(2.7 \%)$. Over half $(51 \%)$ of the patients were unmarried, $45 \%$ married. Graduate level educated or higher comprised of $47 \%$ of the sample, secondary and higher secondary level educated were $29.8 \%$ and $15.2 \%$ respectively. More than two-thirds $(69.5 \%)$ of the respondents belonged to nuclear family and over $70 \%$ of the patients lived in the urban community (Table I).

\section{Prevalence and types of personality disorder:}

Using SCID-II, out of total 151 patients, 94(62\%) were screened as having personality disorders (PDs). The most dominant types of personality disorder found were OCPD (41.5\%) and avoidance (39.4\%). Over one-third $(38.3 \%)$ of the patients were paranoid, $22.3 \%$ were schizo-typal, $18 \%$ borderline and $16 \%$ schizoid disorders. A quarter $(25.5 \%)$ of patients was found depressive, $10.6 \%$ dependent $\&$ $7.4 \%$ anti-social. A few patients were narcissistic $(5.3 \%)$, passive-aggressive $(1.1 \%)$ or histrionic $(2.1 \%)$ (Table II). In terms of severity of OCD, mostly were of moderate severity (44.4\%) or severe $(35.8 \%)$. Patients with extreme OCD were $13.2 \%$ and mild OCD $6.6 \%$ (Table III).

\section{Association between demographic characteristics \& PD}

The mean age of the OCD patients with PD was observed to be significantly higher than those without PD $(p=0.047)$. Male OCD patients were 2.4 (95\% CI of OR: 1.2-4.7) times more likely to have PD than their female counterparts $(p=0.012)$. Ethnic groups other than Muslims tend to be associated with PD more often and carry more than 8 -fold ( $95 \% \mathrm{CI}$ of OR: 8.4-37.2) higher risk of having the condition $(p=0.001)$. Likewise, other occupants were nearly 2 (95\% CI of OR: $0.98-3.74$ ) times more prone to have PD than the students $(p=0.056)$. None of the other demographic characteristics was found to be associated with PD (Table IV). Nearly $60 \%$ of the PDs were found in severe and extreme OCD patients as compared to $41.5 \%$ in mild and moderate form of OCD patients. The risk of having PDs in severe and extreme OCDs is $2.8(95 \%$ CI of OR: $1.4-5.6)$ times higher than that in mild and moderate OCDs (Table V). Nearly $60 \%$ of the PDs were found in sever and extreme OCD patients as compared to $41.5 \%$ in mild and moderate form of OCD patients. The risk of having PDs in severe and extreme OCDs is 2.8 (95\% CI of OR: 1.4-5.6) times higher than that in mild and moderate OCDs (Table VI). 


\section{Association between sex and type of PDs:}

Association between sex and types of PDs shows that out of the 12 types of PDs, paranoid and OCPD demonstrated their significant presence in males ( $p=0.020 \& p=0.042$ respectively), while borderline $\mathrm{PD}$ tend to be more often associated with females $(p=0.023)$. Anti-social PD was considerably higher in males than their female counterparts $(p=0.087)$ (Table VII).

\begin{tabular}{|c|c|c|}
\hline Demographic characteristics & Frequency & Percentage \\
\hline \multicolumn{3}{|l|}{$\mathrm{Age}^{*}(\mathrm{yrs})$} \\
\hline$<20$ & 32 & 21.2 \\
\hline $20-30$ & 74 & 49.0 \\
\hline $30-40$ & 27 & 17.9 \\
\hline $40-50$ & 15 & 19.9 \\
\hline$\geq 50$ & 03 & 2.0 \\
\hline \multicolumn{3}{|l|}{ Sex } \\
\hline Male & 70 & 46.4 \\
\hline Female & 81 & 53.6 \\
\hline \multicolumn{3}{|l|}{ Religion } \\
\hline Muslim & 127 & 84.1 \\
\hline Hindu & 20 & 13.2 \\
\hline Christian & 02 & 1.3 \\
\hline Buddhist & 02 & 1.3 \\
\hline \multicolumn{3}{|l|}{ Occupation } \\
\hline Unemployed & 15 & 9.9 \\
\hline Student & 62 & 41.1 \\
\hline Housewife & 47 & 31.1 \\
\hline Businessman & 04 & 2.6 \\
\hline Service & 19 & 12.6 \\
\hline Others & 03 & 2.7 \\
\hline \multicolumn{3}{|l|}{ Marital status } \\
\hline Unmarried & 77 & 51.0 \\
\hline Married & 68 & 45.0 \\
\hline Separated & 01 & .7 \\
\hline Divorced & 05 & 3.3 \\
\hline \multicolumn{3}{|l|}{ Education } \\
\hline Illiterate & 02 & 1.3 \\
\hline Primary level & 09 & 6.0 \\
\hline Secondary level & 45 & 29.8 \\
\hline Higher Secondary level & 23 & 15.2 \\
\hline Graduate and above & 72 & 47.7 \\
\hline \multicolumn{3}{|l|}{ Habitat } \\
\hline Urban & 109 & 72.2 \\
\hline Rural & 42 & 27.8 \\
\hline \multicolumn{3}{|l|}{ Family status } \\
\hline Nuclear family & 105 & 69.5 \\
\hline Joint family & 46 & 30.5 \\
\hline
\end{tabular}

*Mean $\pm S D=(28 \pm 8.7)$ years; range $=13-60$ years.
TABLE II. Distribution of patients by types of personality disorder $(n=94 *)$

$\begin{array}{lcc}\text { Types of personality disorder } & \text { Frequency } & \text { Percentage } \\ \text { Paranoid } & 36 & 38.3 \\ \text { OCPD } & 39 & 41.5 \\ \text { Avoidant } & 37 & 39.4 \\ \text { Schizoid } & 15 & 16.0 \\ \text { Schizo-typal } & 21 & 22.3 \\ \text { Borderline } & 17 & 18.1 \\ \text { Dependent } & 10 & 10.6 \\ \text { Anti-social } & 07 & 7.4 \\ \text { Narcissistic } & 05 & 5.3 \\ \text { Passive-aggressive } & 01 & 1.1 \\ \text { Depressive } & 24 & 25.5 \\ \text { Histrionic } & 02 & 2.1\end{array}$

*Total will not correspond to $100 \%$ for multiple response

TABLE III. Distribution of patients by severity of OCD $(n=151)$

$\begin{array}{lcc}\text { Severity of OCD } & \text { Frequency } & \text { Percentage } \\ \text { Mild } & 10 & 6.6 \\ \text { Moderate } & 67 & 44.4 \\ \text { Severe } & 54 & 35.8 \\ \text { Extreme } & 20 & 13.2\end{array}$

*Total will not correspond to $100 \%$ for multiple response

TABLE IV. Association between demographic characteristics and personality disorders

\begin{tabular}{|c|c|c|c|c|}
\hline \multirow{2}{*}{$\begin{array}{l}\text { Demographic } \\
\text { characteristics }\end{array}$} & \multicolumn{2}{|c|}{ PD } & \multirow{2}{*}{$\begin{array}{c}\text { OR } \\
\text { (95\% of } \\
\text { Cl of OR) }\end{array}$} & \multirow[b]{2}{*}{ p-value } \\
\hline & $\begin{array}{l}\text { Present } \\
(n=94)\end{array}$ & $\begin{array}{c}\text { Absent } \\
(n=57)\end{array}$ & & \\
\hline Age (yrs) & $29.1 \pm 9.1$ & $26.2 \pm 7.8$ & Not computable & 0.047 \\
\hline \multicolumn{5}{|l|}{ Sex } \\
\hline Male & $51(54.3)$ & 19(33.3) & 2.4 & \multirow{2}{*}{0.012} \\
\hline Female & $43(45.7)$ & $38(66.7)$ & $(1.2-4.7)$ & \\
\hline \multicolumn{5}{|l|}{ Religion } \\
\hline Other religion & $22(23.4)$ & $2(3.5)$ & 8.4 & \multirow{2}{*}{0.001} \\
\hline Muslim & $72(76.6)$ & $55(96.5)$ & $(1.9-37.2)$ & \\
\hline \multicolumn{5}{|l|}{ Occupation } \\
\hline Other occupants & $61(64.9)$ & $28(49.1)$ & 1.9 & \multirow{2}{*}{0.056} \\
\hline Student & $33(35.1)$ & $29(50.9)$ & $(0.98-3.74)$ & \\
\hline \multicolumn{5}{|l|}{ Marital status } \\
\hline Unmarried \& separated & $54(57.4)$ & $29(50.9)$ & 1.3 & \multirow{2}{*}{0.432} \\
\hline Married & $40(42.6)$ & $28(49.1)$ & $(0.67-2.52)$ & \\
\hline \multicolumn{5}{|l|}{ Education } \\
\hline Graduate or above & $41(43.6)$ & $31(54.4)$ & 0.65 & \multirow{2}{*}{0.199} \\
\hline Below graduation & $53(56.4)$ & $26(45.6)$ & $(0.33-1.25)$ & \\
\hline \multicolumn{5}{|c|}{ Habitat } \\
\hline Urban & $67(71.3)$ & $42(73.7)$ & 0.88 & \multirow{2}{*}{0.749} \\
\hline Rural & $27(28.7)$ & $15(26.3)$ & $(0.42-1.86)$ & \\
\hline \multicolumn{5}{|l|}{ Family status } \\
\hline Nuclear & $63(67.0)$ & $42(73.7)$ & 0.72 & \multirow{2}{*}{0.388} \\
\hline Joint & $31(33.0)$ & $15(26.3)$ & $(0.35-1.50)$ & \\
\hline
\end{tabular}

Figures in the parentheses indicate corresponding \%; *Chi-squared Test $\left(\chi^{2}\right)$ was done to analyze the data. 


\begin{tabular}{|c|c|c|c|c|}
\hline \multirow{2}{*}{$\begin{array}{l}\text { Severity } \\
\text { of OCD }\end{array}$} & \multicolumn{2}{|c|}{ PD } & \multirow{2}{*}{$\begin{array}{c}\text { OR } \\
\text { (95\% of } \\
\mathrm{Cl} \text { of OR) }\end{array}$} & \multirow[b]{2}{*}{ p-value } \\
\hline & $\begin{array}{l}\text { Present } \\
(\mathrm{n}=94)\end{array}$ & $\begin{array}{l}\text { Absent } \\
(n=57)\end{array}$ & & \\
\hline Severe \& extreme & $55(58.5)$ & $19(33.3)$ & 2.8 & \\
\hline Mild \& moderate & $39(41.5)$ & $38(66.7)$ & $(1.4-5.6)$ & 0.003 \\
\hline
\end{tabular}

Figures in the parentheses indicate corresponding \%; ${ }^{*}$ Chi-squared Test $\left(\chi^{2}\right)$ was done to analyze the data.

\begin{tabular}{lccc}
\hline \multicolumn{3}{c}{ TABLE VI. Association between sex and types of PDs } \\
\cline { 2 - 3 } Type of PD & $\begin{array}{c}\text { Male } \\
(n=51)\end{array}$ & $\begin{array}{c}\text { Female } \\
(n=43)\end{array}$ & p-value \\
\hline Paranoid & $25(49.0)$ & $11(25.6)$ & 0.020 \\
OCPD & $26(51.0)$ & $13(30.2)$ & 0.042 \\
Avoidant & $18(35.3)$ & $19(44.2)$ & 0.379 \\
Schizoid & $8(15.7)$ & $7(16.3)$ & 0.938 \\
Schizo-typal & $10(19.6)$ & $11(25.6)$ & 0.488 \\
Borderline & $5(9.8)$ & $12(27.9)$ & 0.023 \\
Dependent & $4(7.8)$ & $6(14.0)$ & 0.534 \\
Anti-social & $6(11.8)$ & $1(2.3)$ & 0.087 \\
Narcissistic & $4(7.8)$ & $1(2.3)$ & 0.239 \\
Passive-aggressive & $0(0.0)$ & $1(2.3)$ & 0.457 \\
Depressive & $16(31.4)$ & $8(18.6)$ & 0.157 \\
Histrionic & $1(2.0)$ & $1(2.3)$ & 0.708
\end{tabular}

Figures in the parentheses indicate corresponding \%; *Chi-squared Test $\left(\chi^{2}\right)$ was done to analyze the data.

\section{DISCUSSION:}

The study showed that over $60 \%$ of the patients with OCD have Personality Disorders (PDs) indicating a high prevalence of PDs in Bangladeshi OCD patients. Using SCID-II questionnaire an even higher prevalence of PDs (75\%) was observed in OCD. ${ }^{16}$ This potentially highlights the poor specificity of SCID-II questionnaires. The SCID-II questionnaire was deliberately constructed to be over-inclusive, with a high sensitivity but low specificity, in order to find individuals who might be expected to have a PD. ${ }^{17}$ Therefore, the method of assessment used in this study has led to an over-estimation of personality problems.

The study findings showed that almost half ( $49 \%)$ of OCD patients belonged to the age group 20-30 years with mean age being 28 years (range: 13-60 years) indicating that OCD is disease of young age. The mean age of the OCD patients with PD (29.1 \pm 9.1 years) was observed to be significantly higher than those without PD $(26.2 \pm 7.8$ years $)(p=0.047)$. Early intervention and treatment of OCD may reduce the risk of having PD. Compared to females, male OCD patients were 2.4 times more at risk of having PD $(p=0.012)$. Men with OCD were more likely to have Paranoid, Obsessive-Compulsive, Avoidant and Depressive PDs. In other studies, men with OCD were reported more likely to have personality psychopathology in general than women and antisocial $\mathrm{PD},{ }^{6}$ obsessive-compulsive $\mathrm{PD}^{8}$ and cluster A subtypes in particular. ${ }^{7}$ Most of the types of PDs are more common among men in general population around the world. Researcher found more presence of different types of PDs among men in OCD population. The present study also showed that ethnic groups other than Muslims carry more than 8-fold higher risk of having PDs $(p=0.001)$. Bangladesh is a country of multiple cultures where different ethnic groups believe to coexist. Presence of different religion rituals may aggravate the severity of obsessive-compulsive symptoms, which in turn increase the risk of having PD among patients with OCD. Researcher found that occupants other than students were nearly 2 times more prone to have PD $(p=0.056)$. None of the other demographic characteristics was found to be associated with PDs. Personality Disorders are common and chronic. They occur in $10-20 \%$ of the general population. Approximately $50 \%$ of psychiatric patients have a $\mathrm{PD}$ which is frequently co-morbid with other clinical syndromes. PD is also a predisposing factor for other psychiatric disorders (e.g., substance use disorder, suicide, affective disorders, impulse control disorder, eating disorder and anxiety disorder) in which it interferes with treatment outcomes of many clinical syndromes \& increase personal incapacitation and morbidity. OCD is associated with reduced quality of life as well as high levels of social and occupational impairment. Majority of patients report a gradual worsening of obsession and compulsion prior to the onset of full criteria of OCD, which is followed by chronic course. The nature of the personality pathology is diverse. Persons with PDs generally refuse psychiatric help, deny their problems than persons with anxiety disorders, depressive disorders, and are reluctant to receive treatment. Person with PDs do not feel anxiety 
about their maladaptive behavior. So, OCD patients with co-morbid PDs may have a very poor outcome. They remain undiagnosed and untreated. ${ }^{5}$

There are several limitations of the study which deserve mention. Firstly, the SCID-II questionnaire deliberately constructed to be over-inclusive has led to an over-ascertainment of personality problems and requires a second stage interview in order to improve the likelihood of detecting cases of PD. Secondly, the sample was not sufficiently enough to represent the study population. Further, it was a hospital-based study and, as such the findings of the study cannot be generalized to reference population. Thirdly, patients with Obsessive Compulsive Disorder was diagnosed clinically by single expert consultant due to time limitation, which was not verified by other independent observer.

\section{Conclusion:}

From the findings of the study, it appears that $O C D$ generally affects young people with no sex differential. A substantial proportion of the OCD patients may have PDs. Male OCD patients, non-Muslims and occupants other than students are more prone to have PD. Persons with Personality Disorders are far more likely to refuse psychiatric help and deny their problems. Early intervention is crucial. Parents, family members and friends should be educated properly about the disease and its burden so that they can help the OCD patients to overcome their mental health associated PD.

\section{CONFLICT OF INTEREST}

There was no involvement of pharmaceutical or third party in this research. The fund was provided by research grant committee of BSMMU.

\section{REFERENCES:}

1. Torres AR, Prince MJ, Bebbington PE, Bhugra D, Brugha TS, Farrell $M$, et al. obsessive-compulsive disorder: prevalence, comorbidity, impact, and help-seeking in the British National Psychiatric Morbidity Survey of 2000. American Journalof Psychiatry 2006;163(11): 1978-85.

2. Mohammadi MR, Ghanizadeh a, Rahgozar M, Noorbala AA, Davidian H, Afzali HM,Naghavi HR, Yazdi SAB,Saberi SM, Mesgarpour B, Akhondzadeh S, Alaghebandrad J, Tehranidoost M. Prevalence of obsessive-compul- sive disorder in Iran. BMC Psychiatry 2004;4:2. doi: 10.1186/1471-244X-4-2

3. Feroz AHM, Karim ME, Alam MF, Rahman AHMM, Zaman MM. Prevalence, medical care, awareness and attitude towards mental illness in Bangladesh. Bangladesh Journal of Psychiatry 2006;20(1): 9-36.

4. Rasmussen SA and Eisen JL.The epidemiology and clinical features of obsessive compulsive disorder. Psychiatric Clinics of North America 1992;15(4): 743-58.

5. Sadock BJ, Sadock VA, Ruiz P. Synopsis of Psychiatry. Philadelphia: Wolters Kluwer. 2007.

6. Ronchi P, Abbruzzese M, Erzegovesi S, Diaferia G, Sciuto $\mathrm{G}$ and Bellodi L. The epidemiology of Obsessive-Compulsive Disorder in an Italian Population. European Psychiatry 1992; 7:53-59.

7. Matsunaga $\mathrm{H}$, Kiriike $\mathrm{N}$, Matsui $\mathrm{T}$, Miyata $\mathrm{A}$, Iwasaki $\mathrm{Y}$, Fujimoto $\mathrm{K}$ et al. Gender differences in social and interpersonal features and Personality Disorders among Japanese patients with obsessive-compulsive disorder. Comprehensive Psychiatry 2000;41:266-72.

8. Thompsen PH and Mikkelssen HU. Development of personality disorders in children and adolescents with obsessive-compulsive disorder: a 6-22 year follow-up study. Acta Psychiatrica Scandinavica 1993;87:456-62.

9. Matsunaga H, Kiriike N, Nagata T, Yamagami S.Personality disorders in patients with eating disorders in Japan. International Journal of Eating Disorder 1998; 23(4):399-408.

10. Baer L and Jenike MA. Personality Disorders in obsessive-compulsive disorder. Psychiatric Clinics of North America 1992;15:803-12.

11. Torres AR and Del-Porto JA.Comorbidity of Obsessive-compulsive disorder and Personality Disorders: a Brazilian controlled study. Psychopathology, 1995;28: 322-29.

12. Mataix-Cols $D$, BaerL, Rauch SL, Jenike MA. Relation of factor-analysed symptom dimensions of obsessive-compulsive disorder to Personality Disorders. Acta Psychiatrica Scandinavica 2000;102:199-202.

13. Black DW and Noyes R. Obsessive-compulsive disorder and axis II. International Review of Psychiatry 1997;9: 111-18.

14. BaerL, Jenike MA, Ricciardi JN, Holland AD, Seymour RJ, Minichiello WE, Buttolph ML. Standardized assessment of Personality Disorders in Obsessive-Compulsive Disorder. Archives of General Psychiaty 1990;47: 826-30. 
15. Samuels J, Nestadt G, Bienvenu OJ, Costa PT Jr, Riddle MA, Liang KY, Hoehn-Saric R, Grados MA, Cullen BA. Personality Disorders and normal personality dimensions in obsessive-compulsive disorder. The British Journal of Psychiatry: the journal of mental science, $2000 ; 177(5): 457-62$.

16. Bejerot S, Schlette P, Ekselius L, Adollfson R, Knorring V. Personality disorders and relationship to personality dimensions measured by the Temperament and Character Inventory in patients with obsessive-compulsive disorder. Acta Psychiatrica Scandinavica 1998;98 (3):243-49.
17. Ekselius L, Lindström E, Knorring L, Bodlund O, Kullgren G. Comorbidity among the personality disorders in DSM-III-R. Personality and individual difference 1994; 17(2):155-60. 